Gastroenterologia. 1954;81:71-72

\title{
Experimental Studies in the Splanchnic Circulation
}

E.J.

\author{
Delorme
}

\section{Edinburgh}

Previous methods of estimating red cell content of tissues involving excision of tissues, transillumination, capillary microscopy, and cine-angiography are either inaccurate, limited in scope or do not give quantitative information on changes taking place in living tissues.

By employing a red cell labelling technique (MukL·rjee and Rowlands, 1951) direct reading of the radioactivity of circulating labelled cells can be determined for any given tissue in vivo. By comparing these values with those obtained on a sample of circulating blood taken at the same time in which the total cell content (labelled and unlabelled cells) can be determined by direct cell count, the total cell 